CORROSION FATIGUE OF WELDED JOINTS IN MARINE AND NAVAL

\title{
STRUCTURES: A REVIEW
}

\author{
J. JAGADESH KUMAR ${ }^{1}$, G. DIWAKAR ${ }^{2} \&$ V. V. SATYANARAYANA ${ }^{3}$ \\ ${ }^{1}$ Research Scholar, Department of Mechanical Engineering, K. L. University, Vaddeswaram, Andhra Pradesh, India \\ ${ }^{2}$ Professor, Department of Mechanical Engineering, K. L. University, Vaddeswaram, Andhra Pradesh, India \\ ${ }^{3}$ Professor, Department of Mechanical Engineering, Vidya Jyothi Institute of Technology, Hyderabad, India
}

Throughout the service life, marine/ naval structures experience environmental loading which cause cyclic stress variations in their structural members. These variations can cause fatigue cracking in welded structural details if they are improperly designed. Fatigue life estimation in such dynamic loading conditions is a complex problem and if corrosion along with other geometrical and environmental factors is taken into consideration, the complexity of the problem increases exponentially. The current work, reviews about fatigue failure in welded joints and different factors influencing fatigue life of welded joints with special focus on corrosion fatigue. The scope of the current review also includes a discussion on different fatigue life assessment techniques and methods to improve corrosion fatigue life of welded joints. The current review also presents a comparison of high strength low alloy (HSLA) welds to unalloyed carbon steel welds in terms of corrosion fatigue resistance and strength.

KEYWORDS: Fatigue Testing Machine (FTM), High Strength Low Alloy (HSLA) Steel, Low Plasticity Burnishing (LPB) \& Thermal Barrier Coatings (TBCs)
\end{abstract}

Received: Sep 29, 2017; Accepted: Oct 18, 2017; Published: Nov 04, 2017; Paper Id.: IJMPERDDEC201716

\section{INTRODUCTION}

According to ASTM fatigue is "the process of progressive localized permanent structural changes occurring in a material subjected to conditions that produce fluctuating stresses at some point or points and that may culminate in cracks or complete fracture after a sufficient number of fluctuation". Fatigue failure stages are crack initiation, crack propagation and fracture [1]. Failures occurring in the members due to the situations of dynamic or alternating loading are called fatigue failures. It is generally observed that these failures occur only after a considerable period of service. Fatigue failures typically occur at stresses well below the yield strength, or in some cases above the yield strength but below the tensile strength of the material. These failures are hazardous because they befall without any warning. Typical machine components subjected to fatigue are automobile crankshaft, bridges, aircraft landing gear, etc. When fatigue occurs above $10^{3}$ cycles and is usually in the range of $10^{3}$ to $10^{6}$ cycles it is called high-cycle fatigue model while the low-cycle fatigue model comprises of fatigue in the range of $10^{2}$ to $10^{3}$. The stress levels in high-cycle fatigue is in elastic range and varies from very low to a tune of $2 / 3$ of yield stress whereas in low-cycle fatigue model, the stresses applied often fall in plastic range.

Fatigue analysis of a component made of single material itself is complex as there can be several reasons for failure due to fatigue. Dominique Beghin (2006) quoted that, fatigue life prediction of welded joints is complex, costly and time consuming, due to the diversity of stress concentration locations and heterogeneity of the weld 
metal properties [2].

Extensive research is done on fatigue life prediction of welded joints, as fatigue is one of the main reasons, for the failure in welded joints; however, the research is not exhaustive. There is still lot of scope for exploration in this area, due to the continuous inventions of newer materials, welding techniques and engineering designs.

\section{FACTORS INFLUENCING FATIGUE LIFE OF WELDED JOINTS}

Pollard et al. (1972) concluded that geometry of weld is the most significant aspect in determining the fatigue properties of a weld. Different welding processes influence fatigue strength by producing welds with different degrees of surface roughness and weld metal soundness. It was also concluded that automatic processes prove to be superior to manual processes because they can produce welds with a smoother surface and greater freedom from weld defects such as porosity and slag inclusions. Residual stress due to welding can affect fatigue strength and a moderate increase in fatigue strength can be obtained by thermal stress relief. Localized heating, localized heating and quenching, localized compression and peening proved to be effective in inducing the required compressive stresses and thereby enhancing fatigue strength. The post weld treatments involving local heating or compression are only suitable for treating the ends of longitudinal fillet or gusset welds, whereas peening is applicable to all weld geometries. The microstructures of the weld metal and heat-affected zone have only a negligible impact upon the fatigue strength of welds and are usually masked by the much greater effects of weld geometry and weld defects [3].

Piraprez (1982) examined the effect of preheating and shot-peening, on the fatigue strength of oxygen cutting surfaces. Based on the fatigue test results, shot-peening after cutting increased the fatigue resistance, by $30 \mathrm{MPa}$ to $35 \mathrm{MPa}$ and preheating by about $25 \mathrm{MPa}$, for AE 355 steel [4].

Sperle (1997), in his survey of high strength steels with yield, stress up to 1200MPa found that, material strength has no influence on the fatigue strength of welded joints. The reason was the sharp notch or crack at the weld toes. It was also reported that, when the stress concentration is moderate, the yield strength of the base material can affect the fatigue resistance [5].

Rörup et al. (2004), investigated the influence of mean compressive stresses on the fatigue resistance of a S355 J2 G3 steel welds, fabricated by longitudinal stiffener employing fillet welds. The specimens were made from structural steel S355 J2 G3. It was concluded that, the magnitude of residual stresses influenced the fatigue life resistance of the material, significantly [6].

Johan Martinsson (2005) concluded that, weld geometry and defects strongly influence the fatigue life of the welds and further concluded that, the flux core wire gave low magnitude of defects, compared to solid wire. Also, the importance of applying boundary conditions correctly increases, when the fatigue critical locations are close to the boundary [7].

Barsoum et al. (2009), examined the residual stress effect on the fatigue life of welded structures. In this investigation, the FE-method was used in residual stress state determination. The temperature results from the FE-models were compared with measured results and concluded that, the compressive residual stresses had a beneficial influence on the fatigue resistance [8].

Sakino Yoshihiro et al. (2012) found that, the fatigue lives of the fillet welded joints with laser peening were at 
least 5 times greater than those, without laser peening under the stress range of $250 \mathrm{MPa}, 10$ times or more under $300 \mathrm{MPa}$, 12 times or more under 350MPa and about 5 times under 400MPa. Fatigue strength at $10^{7}$ cycles of the butt-welded joints with laser peening was $300 \mathrm{MPa}$ and 1.5 times greater compared to the specimens without laser peening. Fatigue tests revealed that laser peening dramatically extends the fatigue life and increase the fatigue strength of welded joints [9].

F. Esmaeili et al. (2015) concluded that, the spot-welded arrangement effect had a considerable role in fatigue strength of multi-spot-welded joints. The results obtained from multiaxial fatigue criteria were compared, with the results from experimental fatigue test and concluded that, they were in consonance. Among, the applied criteria, the SWT (SmithWatson-Topper) criterion had the best accuracy, for all types of the specimens. The VF (Varani-Farahani) criterion showed inaccurate prediction of fatigue life, among the employed multiaxial fatigue criteria, for fatigue strength of multi-spotwelded joints, studied in that investigation [10].

\section{FATIGUE LIFE ESTIMATION METHODS}

The popular fatigue life assessment methods can be classified as follows [11];

\section{- Global Methods}

- $\quad$ Nominal stress method.

\section{- Local Methods}

- $\quad$ Hot spot method

- $\quad$ Local stress method

- $\quad$ Local strain method

- $\quad$ Fracture mechanics method

Balasubramanian et. al. (1999), developed a new mathematical model, to predict the fatigue life of Shielded Metal Arc Welded (SMAW) cruciform joints, containing Lack of Penetration (LOP) defect using High strength, quenched and tempered steel (ASTM 517 'F' Grade), as the base material. The model was developed by Response Surface Method (RSM) and Analysis of Variance (ANOVA) technique, was applied to check the validity of the model. By the developed mathematical model, fatigue life could be predicted with $99 \%$ confidence level, for the above-mentioned type of welded joints. The effect of cruciform joint dimensions on fatigue life was analysed in detail and concluded that larger weld sizes, smaller LOP sizes and straight profile fillet welds have better fatigue lives, compared to other combinations [12].

P. J. Haagensen and S J. Maddox (2001), discussed weld improvement methods, on arc welded Steel and Aluminium structures, subjected to fatigue loading. The effect of weld improvement methods, like modification of weld toe geometry by burr grinding, TIG dressing, introduction of compressive residual stresses by hammer/ needle peening on fatigue life of a weld were discussed [13].

Lassen et. al. (2005), investigated a statistical model, where fatigue life and fatigue limit were treated as random variables. Fatigue failure can arise even under modest in-service stresses. Besides, fatigue lives exhibit significant scatter, even under constant amplitude loading in controlled pre-defined conditions. This phenomenon makes statistical approaches inevitable and fatigue life, must be predicted at given probability levels of failure, under defined environment and loading 
conditions, for a given welded detail. The most common approach is to assume that, the nominal applied stress range is the key parameter for the fatigue life, and those other loading parameters, such as the mean stress has a minor effect for welded joints. [14].

A. Chattopadhyay et al. (2011), proposed an efficient shell finite element technique, for obtaining stress data in welded structures relevant for fatigue analyses and showed that, the complete welded structure could be modelled using small number of large shell finite elements. The proposed technique could capture both, the magnitude and the gradient of the hot spot stress, near the weld toe which were necessary to calculate the stress concentration and the peak stress, at critical cross-sections like the weld toe [15].

Hong-Tae Kang et. al. (2012), discussed the primary mechanical parameters, affecting fatigue life of resistance spot-welded joints, which include weld nugget diameter, specimen width, sheet metal thickness, base metal strength, specimen types, and multiaxial loading. Fatigue life prediction methods for spot-welded joints were also discussed, by categorizing them into three approaches, i.e. Load life approach, Linear elastic fracture mechanics approach and Structural stress approach [16].

Teppei Okawa et. al. (2013), developed a fatigue life prediction system for welded structures on crack growth analysis. In that system, the fatigue life was predicted considering the effects of the residual stress and the load sequences by the crack opening and closure simulation. The effects of fatigue strength improvement techniques, such as UIT (Ultrasonic Impact Treatment), were accurately predicted by the new system [17].

Mikheevskiya et. al. (2015) proposed a novel method named Total Life approach, which when applied to welded A-36 steel T-Joint configuration, generated a reasonable estimation of the total fatigue life of the component. This was done by using only the Total Life fatigue crack growth analysis technique, for both constant and variable amplitude loading histories. This enabled, estimating the entire fatigue life of a component, without the need of using division of the fatigue process into crack initiation and propagation stages. It required using only one methodology, i.e., the fracture mechanics based fatigue crack growth analysis. It was also demonstrated that, the Total Life fatigue crack growth method can be used to estimate fatigue lives of smooth specimens that are deemed to be free of initial cracks in engineering sense [18].

D. Radraj (2015), proposed a local SED approach which provides powerful tools, to solve the field problem at sharp notches, thus facilitating the assessment of brittle fracture and fatigue failure of structural members. The size effect on strength was also included. Due to the proposed approach, finite element procedures based on coarse meshes were sufficient, without major loss in accuracy [19].

Shrestha Ranjit et al. (2016), predicted the fatigue life of dissimilar materials welded specimen, using Finite Element Analysis. The study was carried on welding of two dissimilar materials, in which SA106 and STS 304 are the parent materials and M309 is used, as a filler material. Butt welded joint specimen using gas metal arc welding (GMAW) process, was analysed to cyclic loading. The specimen was modelled in ANSYS 15 Workbench. The maximum life was found to be $1 \mathrm{E} 7$ cycles, whereas the minimum life was found to be $2.53 \mathrm{E} 5$, for the given boundary conditions [20].

\section{CORROSION FATIGUE OF WELDED JOINTS}

Welded joints of marine structures are subjected to cyclic loadings, in the corrosive environment of sea water. The combined action of cyclic loading and corrosive environment, often results in significantly lower fatigue performance 
compared to that, under cyclic loading condition in normal environment. Corrosion fatigue could be a simple resultant of fatigue cracking and corrosive attack, or it might be a more complex combination of these two processes.

Takao AOKI et. al. (1983), measured planar defects in the butt-welded joints of high tensile steel, by ultrasonic testing with a point focused angle probe and the results were related to the fatigue life prediction, in air and sea water for the joints containing those defects. It was shown that, there was a reasonably close agreement between the predicted and observed lives for both fatigue and corrosion fatigue. It was concluded that accurate prediction of the fatigue life and corrosion fatigue life is possible, provided the defect shape can be detected by a non-destructive testing with the accuracy equivalent to that obtained in their work [21].

Yantao et. al (2006), concluded that, fatigue failure of welded joints in different media like air, sea water and sea water with cathodic protection occurred around the weld interface and resulted in crack and fracture. It was also concluded that, the corrosion fatigue life of welded joints in seawater was about $1 / 2$ to $1 / 3$ of that in air. Also, the difference between the fatigue life of welded joints, in seawater and air was greater with decreased stress level [22].

Jack Wesley Soape (2012), concluded that, for welded specimens simultaneously experiencing corrosion and fatigue, the fatigue life is governed, by the flaws residing in the weld region, until approximately half of the cross section is lost to the corrosion process [23].

The corrosion fatigue model, proposed by Shu-Xin Li et. al. (2013), showed a good agreement with the experimental test data, at lower stress levels but forecasts more conservative lifetimes, as the stress increases. As part of the research, the Kitagawa-Takahashi diagram was also generated for both test environments, where it is showed that, the fatigue limit can be eliminated in a corrosive environment [24].

Very high cycle fatigue tests were carried out, upto $10^{9}$ cycles on smooth specimens in hot rolled martensiticbainitic steel, under three different conditions i.e. virgin specimens, pre-corroded specimens and specimens under artificial sea water flow, by Ruben et. al. (2015). The fatigue strength of specimen under artificial sea water flow at $3 \times 10^{8}$ cycles was drastically reduced by a factor of $74 \%$, compared to the virgin specimens and of $71 \%$, compared to the pre-corroded ones. The size of the pits was related to the poor corrosion-fatigue strength. The assessment of the crack growth showed that, crack initiation dominates the total fatigue life [25].

\section{METHODS TO IMPROVE CORROSSION FATIGUE LIFE}

Surface treatment is one of the most promising methods, to improve corrosion fatigue strength of structural materials, in service environments. Ebara R et. al. (2001), concluded that, corrosion fatigue life of welded joints can be improved greatly, by coating with tar epoxy resins [26].

Ebara R (2001), demonstrated that, corrosion fatigue strength of KA32 (TMCP) steel can be improved by tar epoxy resin coating and an acceleration of corrosion fatigue crack propagation rate, for KA36 (TMCP) and KAS steel was observed in the higher stress intensity factor range, under sour crude oil environment [27].

Ebara R (2005), reviewed the effect of shot-peening on corrosion fatigue strength of structural materials, through the experimental results on SUP9 and SUP10M steels and concluded that, shot-peening effect can be expected in relatively higher stress level [28].

Douglas J. Hornbach et. al. (2012), carried out a study, primarily on 410 SS, which is an alloy widely used in 
steam turbine applications and concluded that, Low Plasticity Burnishing (LPB) mitigates the stress corrosion effects during cyclic loading, effectively producing a fatigue strength of twice that of shot peening [29].

Fauchais et. al. (2012), proved that, thermal insulation provided by Thermal Barrier Coatings (TBCs), improved component's creep and thermo-mechanical fatigue life, which thereby paved way for high-thrust gas turbine engines [30].

Apart from coatings, there is also active research in the field of metallurgy and material science to find newer alloys and composites for the possible replacement of conventional welded joints used in marine applications, to achieve better corrosion fatigue performance. Few of the newer materials include high strength low alloy (HSLA) steels, duplex stainless steels, high entropy alloys (HEA) etc.

\section{HSLA STEELS AND ITS SUITABILITY IN CORROSION FATIGUE CONDITIONS}

HSLA steels provide better mechanical properties and greater resistance to corrosion than unalloyed carbon steel. HSLA steels have carbon content between $0.05 \%$ to $0.25 \%$ to retain formability and weldability. Other alloying elements comprise upto $2.0 \%$ manganese and small quantities of copper, nickel, nitrogen, niobium, vanadium, chromium, molybdenum, titanium, calcium, rare earth elements, and zirconium. Copper, titanium, vanadium, and niobium, are added for improving the strength. These elements are intended to modify the micro structure of carbon steels, which is usually ferrite-perlite aggregate, to produce a very fine spreading of alloy carbides, in an almost pure ferrite matrix. This eliminates the toughness-reducing effect of a Pearlitic volume fraction, yet maintains and increases the strength of the material, by refining the grain size [31].

S. Sivaprasad et. al. (2006), evaluated fatigue crack growth behaviour of two variants of HSLA steels, used in naval structural applications in air and $3.5 \% \mathrm{NaCl}$ solution. Both the variants showed similar resistance to fatigue crack growth in air. However, in $3.5 \% \mathrm{NaCl}$, the fatigue crack growth resistance of HSLA-80 steel, was greater than HSLA-100 [32].

The A656 Grade 80 steel specification is a high-strength-low-alloy (HSLA), hot rolled structural steel plate, with minimum yield strength of 80ksi. Excellent formability, corrosion resistance and weldability are characteristics of this grade. The excellent strength to weight ratios, make them useful in structural applications, where weight is an issue. As these plates are stronger than mild steel, they can provide high strength in thinner sections at a lower weight. This variant of HSLA can be a potential candidate in naval and marine weld joints, due to its superior mechanical and chemical properties. The key advantage of the HSLA steels is their inherent weldability and attendant lack of preheat requirement, as part of the welding process $[33,34]$.

\section{CONCLUSIONS}

Corrosion fatigue life of welded joints can be greatly improved by surface treatments, like coating with tar epoxy resins, Low Plasticity Burnishing and Thermal Barrier Coating. HSLA welds have better corrosion fatigue resistance and strength, compared to unalloyed carbon steel welds and can be a better substitute, to the conventional welded joints used in marine and naval applications.

\section{SCOPE FOR FURTHER RESEARCH}

Corrosion Fatigue Strength of different grades of HSLA steel welded joints, can be investigated by conducting experimental runs on Fatigue Testing Machines. Finite Element Analysis can also be implemented, by using the Fatigue 
Tool of the Ansys Workbench, to predict the Fatigue Life of HSLA steel welded joints. The authors took up this research, as part of doctoral thesis work of one of the authors.

\section{REFERENCES}

1. Andresen. P \& Antolovich. B, Fatigue and Fracture. ASM Handbook, 1997.

2. Dominique Beghin, "Fatigue of Ship Structural Details", "Technical and Research Bulletin 2-31", Society of Naval Architects and Marine Engineers, New Jersey, 2006.

3. B. Pollard and R. J. Cover, "Fatigue of Steel Weldments", Welding Research Supplement, Vol 83, 1972.

4. E. Piraprez, "Fatigue strength of flame cut plates", 1982. [Online]. Available: http://dx.doi.org/10.5169/seals-28902.

5. Jan-Olof Sperle, "High Strength Sheet and Plate Steels for Optimum Structural Performance," Conf. Iron Steel - Today, Yesterday Tomorrow Proc. 250th Anniversary Swedish Ironmasters Assoc., 1997.

6. J. Rörup and W. Fricke, "IIW XIII-2007-04 Mean compressive stress - Experimental and theoretical investigation into the influence on the fatigue strength of welded structures," Technical University Hamburg-Harburg Ship Structural Design and Analysis, 2004.

7. Johan Martinsson, "Fatigue Assessment of Complex Welded Steel Structures", TRITA-AVE 2005:02, ISBN 91-2783-968-6, 2005.

8. Z. Barsoum and I. Barsoum, "Residual stress effects on fatigue life of welded structures using LEFM," Engineering Failure Analysis, vol. 16, no. 1, pp. 449- 467, 2009.

9. Sakino Yoshihiro, Sano Yuji, Sumiya Rie \& Kim You-Chul, "Fatigue Life Enhancement of Fillet and Butt Welded Joints after Laser Peening”, Transactions of Joining and Welding Research Institute, Vol.41, No. 1, 2012.

10. F. Esmaeili, A. Rahmani, S. Barzegar \& A. Afkar, "Prediction of fatigue life for multi-spot welded joints with different arrangements using different multiaxial fatigue criteria”, Materials and Design, Vol. 72, page 21-30, 2015.

11. Juha Peippo, "A modified nominal stress method for fatigue assessment of steel plates with thermally cut edges", Doctoral Thesis, Lappeenranta University of Technology, Lappeenranta, Finland, December 2015.

12. V. Balasubramanian, B. Guha, "Fatigue life prediction of shielded metal arc welded cruciform joints containing LOP defects by a mathematical model", International Journal of Pressure Vessels and Piping, Elsevier Science Ltd, Vol 76, page 283-290, 1999.

13. Haagensen, P. J. Maddox, S. J., "IIW Recommendations on Post Weld Improvement of Steel and Aluminium", IIW Commission XIII, 2001.

14. T. Lassen, Ph. Darcis, And N. Recho, Fatigue Behavior of Welded Joints Part 1 - Statistical Methods for Fatigue Life Prediction, Supplement to The Welding Journal, page 183-187, December 2005.

15. A Chattopadhyay, G. Glinka, M. El-Zein, J. Qian, and R. Formas, "Stress Analysis and Fatigue of welded structures," Welding in the World, Vol. 55, Issue. 7-8, page 2-21, 2011.

16. Hong-Tae Kang \& Yung-Li Lee, "Fatigue Life Prediction Methods of Resistance Spot-Welded Joints", Metal Fatigue Analysis Handbook, page 429-460, 2012.

17. Teppei Okawa, Tetsuro Nose, Hiroshi Shimanuk, Tamaki Suzuki, "Fatigue Life Prediction of Welded Structures Based on Crack Growth Analysis", Nippon Steel Technical Report No. 102, page 51-56, January 2013. 
18. S. Mikheevskiya, G. Glinkaa, T. Cordes, "Total life approach for fatigue life estimation of welded structures", 3rd International Conference on Material and Component Performance under Variable Amplitude Loading, Elsevier Ltd, 2015.

19. D. Radaj, "State-of-the-art review on the local strain energy density concept and its relation to the J-integral and peak stress method", Fatigue \& Fracture of Engineering Materials \& Structures, Vol. 38, Issue 1, page 2-28, 2015.

20. S. Ranjit and W. Kim, "Fatigue Analysis of Dissimilar Materials Welded Specimen Using Finite Element Analysis," Vol. 11, Issue. 5, page 3390-3393, 2016.

21. Takao AOKI, Keishi NAKANO, Hiroaki FUKUHARA, Akira OKADA, Shigeo KOBA YASHI, Katumi KIMURA and Michio INAGAKI, "Fatigue Life and Corrosion Fatigue Life Prediction of Welded Joints of Structural Steel Containing Planar Defects”, 106 ${ }^{\text {th }}$ ISIJ Meeting, Akita University in Akita, October 1983.

22. Yantao Li \& Baorong Hou, “Corrosion fatigue of welded joints of steel for marine platform”, Indian Journal of Engineering \& Materials Sciences, Vol. 13, No. 5, page 467-470, 2006.

23. Jack Wesley Soape, “Investigating the Effects of Corrosion on The Fatigue Life of Welded Steel Attachments”, Master of Science thesis, Texas A\&M University, 2012.

24. Shu-Xin Li, R. Akid, "Corrosion fatigue life prediction of a steel shaft material in seawater", Engineering Failure Analysis, Vol. 34, page 324-334, 2013.

25. Ruben Pérez-Mora, Thierry Palin-Luc, Claude Bathias, Paul C. Paris, "Very high cycle fatigue of a high strength steel under sea water corrosion: A strong corrosion and mechanical damage coupling”, International Journal of Fatigue, Elsevier Ltd, Vol 74, page 156-165, 2015.

26. Ebara $R$, “Improvement of corrosion fatigue strength of materials by various surface treatments", Transactions on Engineering Sciences, Vol 33, 2001.

27. Ebara R, “Corrosion fatigue behavior of ship hull structural steels”, ICF10, Honolulu, Hawaii, Japan, Vol 32, 2001.

28. Ebara R, "Shot-peening effect in corrosion fatigue strength of structural materials" $11^{\text {th }}$ International Conference on Fracture, page 3-8, 2005.

29. Douglas J. Hornbach and Jeremy E. Scheel, "Improving Corrosion Fatigue Performance \& Damage Tolerance of 410 Stainless Steel via LPB”, Proceedings of PowerGen 2012, Session 11C1, Steam Turbine Reliability, Availability and Efficiency, December 11-13, 2012, Orlando, FL.

30. P. Fauchais and A. Vardelle, "Thermal Sprayed Coatings Used Against Corrosion and Corrosive Wear", Advanced Plasma Spray Applications, Dr. Hamid Jazi (Ed.), ISBN: 978-953-51-0349-3, InTech, 2012.

31. Danijela A. Skobir, "High-strength low-alloy (HSLA) steels: Visokotrdna malolegirana (HSLA) konstrukcijska jekla," Materiali in Tehnologije, Vol. 45, Issue 4, page 295-301, 2011.

32. S. Sivaprasad, S. Tarafder, V. R. Ranganath, M. Tarafder, and K. K. Ray, "Corrosion fatigue crack growth behaviour of naval steels, " Corrosion Science, Vol. 48, Issue 8, Elsevier Ltd, page 1996-2013, 2006.

33. T. W. Montemarano, B. P. Sack, J. P. Gudas, M. G. Vassilaros, and H. H. Vanderveldt, "High Strength Low Alloy Steels in Naval Construction”, Journal of Ship Production, Vol. 2, Issue 3, page 145-162, August 1986.

34. A S. Tawengi, A. Sedmak, V. Grabulov, "Cold Weld Cracking Susceptibility of High Strength Low Alloyed (HSLA) Steel Nionikral 70”, Metalurgija, ISSN 0543-5846, Vol. 53, Issue 4, 624-626, 2014. 